\title{
The Split initiative, chapter 2
}

\author{
Igor Švab ${ }^{1}$, Ivančica Pavličević ${ }^{2}$ \\ ${ }^{1}$ Department of family medicine, University of \\ Ljubljana, Medical faculty \\ ${ }^{2}$ Department of Family Medicine University of Split \\ School of Medicine, Split, Croatia \\ Corresponding author: \\ Igor Švab \\ University of Ljubljana \\ Medical faculty \\ Department of family medicine \\ Poljanski nasip 58 \\ 1000 Ljubljana, Slovenia \\ igor.svab@mf.uni-lj.si \\ Tel.: + 386143869 15; Fax.: + 38614386910
}

Received: 10 April 2014; Accepted: 19 April 2014

Copyright (C) 2014 by Academy of Sciences and Arts of Bosnia and Herzegovina. E-mail for permission to publish: amabih@anubih.ba

For decades, family medicine was struggling to gain its academic recognition. Now it is safe to say that the success of academic development of family medicine in Europe has been remarkable. Family medicine has been successful in creating its theoretical background and in promoting itself as an academic discipline (1). Throughout Europe, academic departments of family medicine have been established and it is now customary that every student at medical school is taught family medicine as a part of obligatory curriculum (2). Specific training for family medicine is being recognised as a standard for modern patient care. It is ac- cepted in the EU and aspired to by most of the countries that want to join the EU (3).

When a discipline reaches this level of development, international collaboration within the discipline must reflect it as well. Doctors of family medicine no longer meet solely as individuals sharing their experiences in everyday work. They also meet as experts sharing their experiences in education and research. Often they do not do this as individuals, but as representatives of institutions: departments of family medicine and national colleges.

The creation of the Split initiative was a result of such a development. The first meeting in Split marked the first ever organised gathering of family medicine departments from former Yugoslavia. The meeting was a success, not only in getting the departments together, but also in publishing most of the key papers in an international journal (1).

Nevertheless, for an activity to be successful, one successful attempt is not enough. We are therefore proud to present the publication, based on the presentations of the second meeting of the Split initiative. This in itself is a proof of the vitality of the discipline and the quality of the teaching of family medicine in the countries that have participated in this event.

The theme of the first meeting of the Split Initiative (held in Split in 2011) was about modern trends in teaching family medicine in medical schools. Selected articles of this 
meeting were published in thematic issue "Contemporary Medical Teaching in Family Medicine" of the journal Acta Medica Academica Vol 41, No 1, 2012 (http://www.ama. ba/index.php/ama/issue/ view/18).

The second meeting (Ljubljana 2013) was on international cooperation in academic family medicine. The selected works (International Textbook of Family Medicine: The application; Satisfaction with the Program of School Bullying Prevention and Mental Health Promotion - Cross Sectional Study among Primary School Pupils in Mostar; Final year medical students' understanding of family medicine; Importance of international networking in academic family medicine; Academic cooperation in family medicine: a viewpoint from Split; Research projects in family medicine funded by the European Union and Fundamental communication skills in medical practice as small elective subject) of the this meeting are presented in this issue of Acta Medica Academica.

We believe that these reports offer to international readers both valuable ideas and inspiration for analysis and initiative on advancement of international cooperation in academic family medicine. There is no reason, rational, professional, or technical why the international collaboration in this medical field would not follow and utilize the paths of cooperation already tested and developed in other medical fields $(1,4)$. This means that the work should be widened from gatherings (meetings, symposia and congresses) to collaboration in applying to international research grants, exchange of students and scientists, multicentre scientific collaboration and all other models that have been confirmed as efficient in most of other fields of academic medicine. We dare to suggest that, owing to specificities of work in family medicine, like the early contact with patients, direct and early encounter of the disease and orientation towards patients' family and social life, family medicine may develop additional, novel and original models of international collaboration. Our field of work is marked with special needs for patient-centred care, which encompasses extended communication with patients, permanent empathy and understanding, and the first, and thus maybe the most important point of patient-physician shared decision making (5). In this respect, we believe that the Split Initiative will in due time bring about novel and valuable pieces of contribution to various aspects of medical care for people with health problems in the widest sense of the health needs of the contemporary time.

Conflict of interest: The authors declare that they have no conflict of interest.

\section{References}

1. Pavličević I, Švab I. Family medicine defines its academic niche: The Split Initiative. Acta Med Acad. 2012;41(1):1-3.

2. Evans PR. Medicine in Europe: The changing scene in general practice in Europe. BMJ. 1994;308 (6929):645-8.

3. Marušić $M$, editor. Curriculum of the integrated pregraduate and graduate program in medicine [in Croatian]. Split: School of Medicine, University of Split; 2011.

4. Green LA. The research domain of family medicine. Ann Fam Med. 2004;2(Suppl 2):S23-S9.

5. Pavličević I, Simi S. Patient input is important: patients should make decisions for their treatment together with their doctors [in Croatian]. Medix. 2014;20(109/110):116-9. 